\title{
o capital e a ARMADILHa DA dívIDA
}

CAPITAL AND THE DEBT TRAP: LEARNING FROM COOPERATIVES IN THE GLOBAL CRISIS,

de Sanchez, Claudia e Roelants, Bruno. Hampshire: Palgrave Macmillan, 2011.

PAUL SINGER

Em Capital and the debt trap: learning from cooperatives in the global crisis, Claudia Sanchez e Bruno Roelants analisam a transformação que o capitalismo sofreu pela globalização da economia mundial que coincidiu com o triunfo da contrarrevolução neoliberal no chamado Mundo Livre, num momento em que a Guerra Fria se aproximava de seu auge e também do seu fim, no final dos anos 1970. Os autores também oferecem uma análise da presente crise econômica internacional à luz das mudanças trazidas pela Terceira Revolução Industrial — a da informática e da internet - , que tornaram possível a hegemonia do capital financeiro em plano mundial, matriz de crises sucessivas que lhe são inerentes. O que aparece às classes dominantes como. "sociedade do conhecimento" se torna exclusão, principalmente pelo desemprego, para os trabalhadores.

Enquanto a série de crises iniciada em 2007 tem atraído todas as atenções, um capitalismo de novo tipo surge da penumbra, produto da desregulação do capital financeiro e de nova onda de privatização dos principais serviços públicos que, por sua essencialidade para a sobrevivência dos mais pobres, serviços sociais porque deveriam ser acessíveis a todos. A sua privatização, agora justamente nos países mais afetados pela crise e, portanto, pelo desemprego, exclui do uso desses serviços os menos aquinhoados, aprofundando a desigualdade e, portanto, a injustiça social - o que explica a expansão mundial dos "indignados", em sua maioria jovens que percebem que o capital financeiro, simbolizado por Wall Street, e suas crises lhes roubam um futuro que as conquistas democráticas das gerações anteriores deveriam ter-lhes assegurado.

A redução dos controles nacionais das trocas comerciais e da movimentação dos capitais especulativos entre os países afiliados à OMC e ao FMI removeu os obstáculos à centralização global dos capitais. Atualmente, cadeias internacionais de produção e distribuição de 
bens e serviços, interligadas por conglomerados financeiros, dominam segmentos inteiros da economia mundial, o que explica a subserviência de governos nacionais democraticamente eleitos às exigências do capital financeiro global, representado por agências intergovernamentais como o FMI e o Banco Central Europeu.

O livro procura descrever a trajetória que está sendo construída pelas crises sucessivas, implicando maior destruição do que geração de riqueza. Essa trajetória é composta por três armadilhas que se fecham sequencialmente, aprisionando os que se endividaram porque acreditaram que a oferta de crédito pelos bancos jamais seria interrompida.

A primeira armadilha é a do consumo. Nos EUA, a renda da população trabalhadora estagnou, sem interrupção, no entanto, do crescimento do consumo. Entre 1992 e 2000 , o crescimento do PIB se baseou principalmente no aumento das compras a crédito de moradias e automóveis. Em 1990, a soma das dívidas das famílias nos EUA era igual a $85 \%$ de sua renda; dez anos depois a soma das dívidas já era igual a $101 \%$ de sua renda. Em 2007, quando estourou a crise, as dívidas das famílias comprometiam 139\% de suas rendas. A desregulamentação financeira permitiu que o povo "prosperasse" enquanto o país se desindustrializava. Quando a demanda por imóveis e automóveis naturalmente se esgotou, a armadilha do consumo aprisionou milhões de famílias, muitas das quais foram duplamente punidas: perderam o trabalho e os bens adquiridos.

A segunda armadilha é a da liquidez. Quando a crise se desencadeia, os empréstimos cessam, inclusive entre os bancos, porque ninguém mais confia em que eles serão pagos no vencimento. A quase bancarrota dos maiores bancos acarreta a paralisação do crédito, ou seja, quase todas as compras têm de ser pagas imediatamente com dinheiro. Ora, como ninguém tem dinheiro porque a crise acarreta forte queda das atividades com as quais os consumidores ganham seu dinheiro, o volume de compras se contrai. Os que ainda ganham tratam de guardaro seu dinheiro em casa, embora lá ele não renda:o pânico sobrepuja a cobiça. O meio circulanteéentesourado, portanto deixa de circular, exceto o pouco dinheiro gasto com compras de bens e serviços indispensáveis.

Os efeitos conjugados das armadilhas do consumo e da liquidez compõem a terceira armadilha: a da dívida. São suas vítimas não só os consumidores que se endividaram, mas todos os outros que tomaram empréstimos para investir. Nos EUA, a hegemonia financeira fez com que o recurso às dívidas se generalizasse: a informática tornou a participação nas operações da Bolsa muito fácil, de modo que a especulação financeira virou um esporte de massas. "Pela primeira vez na história da humanidade", afirmam os autores, "a especulação é a principal 
[1] “Só em 1997 houve 599 fusões bancárias nos EUA, reduzindo o número total de bancos de cerca de 14000 para $9143 . "$ fonte de geração de renda. As firmas de Wall Street haviam assumido dívidas num total equivalente a 32 vezes o seu capital próprio."

A financeirização (isto é, o crescimento não só do volume de dinheiro manipulado pelo setor financeiro como também da influência e, sobretudo, do podereconômico e político dos bancos e fundos de investimento) deslocou o controle das empresas dos diretamente interessados - acionistas, assalariados, gerentes, fornecedores e clientes - para os credores, que frequentemente assumem o papel de controladores do capital acionário da empresa. Os credores, no entanto, não participam diretamente da vida da firma e tampouco têm interesse em sua continuidade. Quando se tornam controladores, o seu único objetivo é recuperar o que emprestaram e o máximo de ganhos adicionais. Por causa disso, o controle de empresas da economia real - industriais, agropecuárias, comerciais e prestadoras de serviços à população - pelo capital financeiro acarreta muitas vezes o seu fechamento prematuro.

O processo se acentuou em 1992, quando o governo dos EUA pediu aos fundos de pensão (que estavam subcapitalizados) que tratassem de reestruturar e extrair o máximo de lucro de qualquer empresa no exterior em que haviam investido. A ocasião era propícia, pois a crise do endividamento externo nos países em desenvolvimento, particularmente nos da América Latina, os havia forçado a abrir suas economias e suas empresas recém-privatizadas à aquisição por estrangeiros. Os bancos da tríade EUA, Europa e Japão participaram ativamente dessa globalização, engajando-se em fusões e aquisições. Os bancos que não se lançaram nessas empreitadas logo foram adquiridos por outros ${ }^{1}$.

Criou-se assim uma nova contradição: a concentração do capital, frequentemente por iniciativa do capital financeiro, fez com que surgisse uma nova classe de firmas consideradas grandes demais para falir. São firmas de tal forma interligadas financeiramente que se alguma das maiores falir leva consigo todas as demais. Isso se verificou na prática em setembro de 2008: a quebra do banco Lehman Brothers contagiou os maiores bancos de investimento, fazendo com que a crise financeira, até aquele momento restrita aos EUA, se alastrasse pelo resto do mundo.Aepidemia de falências só não ocorreu porque os governos nacionais injetaram trilhões de dólares nos bancos para salvá-los.

A submissão de uma parte cada vez maior das empresas a capitais financeiros, para os quais elas não passam de veículos para a obtenção de ganhos especulativos de curto prazo, as torna mais vulneráveis às crises produzidas pelo fechamento das armadilhas do endividamento. Para o bem comum, no entanto, toda empresa deveria ser controlada 
por aqueles diretamente interessados em sua continuidade e em sua robustez produtiva, comercial e financeira. Um indício dessa mudança de opiniãoé a recente concessão do Prêmio Nobel de Economia a Elinor Ostrom, notória defensora da tese de que a administração dos recursos que são propriedades comuns da coletividade deve ser confiada a quem está realmente interessado em sua preservação, ou seja, à própria coletividade. Ela constata que "falta uma teoria adequadamente especificada da ação coletiva pela qual um grupo de interessados pode se organizar voluntariamente para reter os resultados de seus esforços".

Sanchez e Roelants oferecem elementos para a construção dessa teoria mediante o estudo de quatro cooperativas, que são exemplos representativos de ações coletivas voluntariamente organizadas e que obtêm êxito em se resguardar das crises engendradas pelos excessos especulativos dos capitais financeiros. Embora distintos, os quatro casos são bastante representativos de diferentes facetas do cooperativismo contemporâneo.

O primeiro é o de uma cooperativa de mergulhadores e pescadores localizada em Natividad, uma pequena ilha na costa do México, em que moram cerca de oitenta famílias, que vivem da captura de abalones, um marisco muito raro e valioso. Criada em 1942, a cooperativa explora áreas marítimas por concessão do governo. Nos anos 1980, a corrente marítima El Niño aqueceu as águas nessas áreas, o que reduziu o estoque de mariscos, levando à superexploração das reservas de abalones tanto pela cooperativa como pela pesca ilegal de gente de fora. No fim da década a cooperativa conseguiu controlar as práticas predatórias e evitar se envolver numa corrida por ganhos em curto prazo. Adotou uma abordagem científica ambiental e contratou um biólogo. Durante a crise, a assembleia de sócios da cooperativa decidiu fechar uma zona marítima à pesca por quatro anos. Graças à cessação da pesca, os abalones se reproduziram. Quando a pesca nessa zona foi retomada, a cooperativa obteve mais benefícios do que havia sido esperado.

O biólogo da cooperativa propôs que ela investisse em reservas marítimas, tendo em vista assegurar que no futuro houvesse disponibilidade de abalones, pepinos-do-mar e caracóis marítimos. A proposta foi aprovada e a cessação da pesca em determinado espaço reduziu a receita anual da cooperativa em 300 mil dólares, mas os membros esperam que o sacrifício seja compensado no futuro. As concessões de pesca deverão ser renovadas em 2012, e os membros da cooperativa têm bons motivos para esperar que consigam a renovação, o que lhes permite planejar a longo prazo a preservação das áreas de pesca e o desenvolvimento da cooperativa.

O segundo caso estudado é o da Ceralep, uma empresa francesa de pequeno porte fundada em 1921 que produz isoladores de cerâ- 
[2] Um deles se suicidou na fábrica, deixando uma carta em que revelou que não suportava mais a pressão, muito provavelmente decorrente da espera inerte pelo fim de tudo que dava sentido a sua vida. mica. Em 1973 ela se fundiu com outro importante produtor e desde então se tornou a única companhia na França que produz isoladores cerâmicos muito grandes. Em 1989, a Ceralep foi adquirida pela firma suíça Laufen, que a revendeu em 1993 à austríaca Ceram. Essas transações sucessivas fizeram a Ceralep passar por três controladores de diferentes nacionalidades no espaço de vinte anos. Tanto os suíços como os austríacos tentaram debalde se apoderar da tecnologia dos isoladores cerâmicos.

Em 2001, a Ceralep passou a ser controlada pela firma estadunidense PPC Insulators, que começou a agir de forma estranha: demitiu o diretor, mas atendia sem hesitação os pedidos de aumentos salariais dos empregados. A produção caiu muito e os trabalhadores não tinham o que fazer, o que os envolveu num clima extremamente desmoralizante, que se agravou quando os empregados descobriram que a PPC Insulators planejava fechar a Ceralep. É preciso compreender que o fechamento de uma firma que funcionava com êxito há oitenta anos deve ter sido um evento trágico para seus empregados, muitos dos quais passaram grande parte de suas vidas nela e certamente não viam qualquer perspectiva de emprego em outra firma².

Os operários decidiram resistir à liquidação da empresa. Impediram diversas tentativas de remoção de máquinas bloqueando a entrada de caminhões na fábrica. Estas ações impediram efetivamente os controladores de fechar a firma, levando-os a entregar, em 2003 , uma petição de falência, o que possibilitou mais tarde a compra da massa falida pelos empregados. Estes imediatamente escreveram uma carta aberta ao promotor distrital, ao síndico da falência e ao prefeito do departamento de Drôme denunciando que a administração e os acionistas tencionavam quebrar a empresa e condenar os 150 operários e o tecido econômico e social do distrito de Saint-Vallier.

Começou então uma batalha para evitar a destruição da Ceralep. Os trabalhadores se mantiveram unidos e contaram com a ajuda da União Regional de Cooperativas Operárias e da gente simples da comunidade: 802 pessoas doaram um total de 50 mil euros para integrar o capital de giro da futura cooperativa; o fundo francês Socoden de solidariedade das cooperativas operárias emprestou 100 mil euros; o banco cooperativo Crédit Cooperatif também contribuiu até que o milhão e meio de euros necessário para estabelecer a cooperativa fosse reunido.

Os apoios obtidos que ajudaram a impedir o fechamento da Ceralep e asseguraram sua continuidade na forma de um empreendimento cooperativo autogestionário confirmam a veracidade das afirmações contidas na carta aberta dos trabalhadores: a ameaça do fechamento da Ceralep de fato condenaria não só os 150 operários da empresa como também o tecido econômico e social da região. 
Todas as autoridades públicas da região, da municipalidadee a associação de municipalidades apoiaram o projeto dos operários, dando-lhe uma ajuda substancial. A racionalidade da Ceralep foi distorcida por investidores absenteístas em ininterrupta sucessão, que se tornaram controladores à distância e trataram a firma como uma ficha trocável numa cadeia global de suprimentos. Esta racionalidade levou a firma à bancarrota. Uma vez removida a causa, a companhia na forma de cooperativa está indo bem, pois o controle foi entregue aos diretamente interessados.

O terceiro caso estudado no livro em exame é o do Grupo de Cooperativas de Crédito Desjardins, queéa mais importante instituição financeira da província canadense de Québec e a sexta maior do Canadá. Com ativos no valor de US $\$ 155,5$ bilhões, éum dos principais atores financeiros e econômicos da nona maior economia do mundo. Desjardins é também o maior empregador privado de Québec com 39 mil empregados e está entre os maiores empregadores do Canadá, com um total de 42 mil empregados no país. Apesar de todo esse poderio econômico, financeiro e empresarial, Desjardins não procura maximizar o retorno sobre o investimento dos acionistas, mas assegurar serviços satisfatórios para os seus 5,8 milhões de membros proprietários, dos quais 5,4 milhões em Québec, que constituem 70\% da população da província.

O Grupo Cooperativo Desjardins, criado há 110 anos para atender às necessidades financeiras de pequenos agricultores, produtores e assalariados, é formado por 481 cooperativas de crédito locais autônomas, que em conjunto o possuem e controlam. Os autores se detêm na história do Grupo Desjardins porque se trata de um dos maiores conglomerados financeiros do mundo que, num período em que o capital financeiro se globaliza e conquista incontrastável hegemonia na economia capitalista mundial, se mantém fiel à sua missão cooperativa e a seus membros-clientes pertencentes às classes trabalhadoras, sem com isso perder a competitividade.

O Grupo Desjardins conseguiu democratizar e descentralizar os serviços financeiros, tornando-os acessíveis a todas as classes e os difundindo pelas comunidades locais de Québec. Fez com que várias gerações de quebequenses aprendessem a agir coletivamente para desenvolver suas economias locais e adquirissem através de suas caisses scolaires os conhecimentos básicos de como poupar. Atualmente, 6258 presidentes e membros de diretorias das cooperativas de crédito locais aprenderam como um banco funciona e são responsáveis pela sua supervisão.

O grupo desenvolve uma oferta integrada de crédito a meio milhão de negócios, que são seus clientes. Para alcançar tais resultados, teve de construir delicado equilíbrio entre as imposições da concorrência 
financeira e os seus objetivos sociais e entre a segurança financeira de longo prazo de seus membros e as aspirações de curto prazo de seus membros dos mesmos. Ao fazer isso, Desjardins se opõe às armadithas do consumo e da dívida analisadas acima. Na realidade, não gera risco sistêmico, mas apoia o desenvolvimento econômico e social de longo prazo e promove a igualdade e a confiança.

Aestruturação das caisses num agrupamento horizontal desencadeou um forte potencial econômico e social; em vez de permanecerem estruturas isoladas, como eram no começo e poderiam ter permanecido, as cooperativas de crédito locais do Grupo Desjardins conseguiram criar um dos maiores grupos financeiros da América do Norte, sem perder sua capilaridade e continuando totalmente dedicadas à prestação de serviços ao cidadão local e aos negócios locais. A tendência a um excesso de fusões foi controlada, o perigo de que as subsidiárias - seguradoras, fundos de capitalização e fundos de investimentos regionais - pudessem aumentar sua influência em termos de gestão tecnocrática foi igualmente evitado por uma série de reformas de governança sucessivas que incrementou o controle sobre as subsidiárias.

Ao expandir a lógica cooperativa de priorizar a base das cooperativas locais para um sistema tão amplo como a província de Québec, com seus quase 8 milhões de habitantes, Desjardins foi o promotor de uma mesoeconomia, tendo sido por mais de um século um dos principais atores no desenvolvimento de comunidades locais em Québec, além de ter desempenhado um papel-chave na estabilidade financeira do Canadá.Além disso, contra as assimetrias de informação, que muitos interessados sofrem, como é o caso de clientes de grandes instituições financeiras, onde a confiança dos clientes está sendo superada por arranjos opacos e segmentados de contrapartes, Desjardins não apenas nutre a noção de um movimento de proprietários-clientes ao qual se dedica, mas fornece aos últimos informações sobre o grupo de negócios, textos de discussão para ajudá-los a formar opinião na tomada de decisões e lhes oferece treinamento para ajudá-los a administrar suas cooperativas locais. A história de Desjardins também demonstra que crises sucessivas, como a Grande Depressão de 1929, várias crises nos anos 1980 e 1990, e a atual crise global, em vez de ameaçar a existência do grupo de fato a reforçaram, além de lhe dar oportunidade de realizar inovações institucionais e melhorar sua missão fundamental: a de servir seus membros.

O quarto e último caso teve por objeto o Grupo Corporativo Mondragon. Trata-se de um grupo horizontalmente integrado por mais de 110 cooperativas industriais, de serviços, finanças, distribuição, educação e pesquisa, centrado na cidade de Mondragon, na região basca da Espanha. Em 2010, era um grande conglomerado produzin- 
do eletrodomésticos, máquinas-ferramentas, componentes de computadores, mobília, instalações de escritório, materiais de construção, transformadores, componentes de automóveis, moldes para ferro fundido, sistemas de resfriamento, equipamento médico, alimentos e outras manufaturas. Desenvolve uma série de atividades de serviços comoengenharia, urbanismo, pesquisas em setores industriais, nanotecnologia, e compreende uma grande cadeia de supermercados, um banco e uma universidade. É considerado o maior complexo cooperativo do mundo, sendo a maior organização empresarial do País Basco e a sétima da Espanha.

A criação do Grupo Corporativo Mondragon foi inspirada pelo padre José Maria Arizmendiarreta, que em 1941, aos 26 anos, tornou-se pároco de Mondragon, dois anos após a guerra civil que havia ensanguentado a Espanha, na qual combateu ao lado dos republicanos. A pobreza reinava em Mondragon, cuja única grande empresa era uma metalúrgica que oferecia uma escola profissional para os filhos de seus operários. O jovem pároco tentou convencer a família proprietária da empresa a abrira escola aos demais jovens da cidade, mas não teve êxito. Partiu então para a fundação de outra escola profissional, aberta a todos os moradores de Mondragon. Para obter os recursos necessários o padre promoveu uma campanha bem-sucedida de contribuições entre a população, recebendo apoio de $15 \%$ de seus moradores.

A nova Escola Politécnica foi a matriz do complexo cooperativo: cinco ex-alunos adquiriram - também com a ajuda da população uma empresa falida, que se tornou a cooperativa ULGOR, fundada em 1956. O padre ajudou na empreitada e desde então passou a ser uma espécie de orientador espiritual da cooperativa. Um dos princípios adotados foi limitar o tamanho da cooperativa para que a autogestão da mesma pudesse contar com a participação consciente de todos os sócios. Quando a ULGOR passou a crescer, estimulada pela demanda por seus produtos, partes dela se separaram e foram transformadas em novas cooperativas: a Arrasate, fundada em 1958, fabrica máquinas-ferramentas; fundadas em 1963, a Copreci produz componentes de fogões domésticos e industriais e a Ederlan produz peças fundidas. As três eram parte da ULGOR e continuaram vendendo quase toda sua produção para esta última.

As cooperativas desmembradas foram unidas à cooperativa matriz, formando todas uma cooperativa de segundo grau; nesta os excedentes das cooperativas singulares são somados e redistribuídos por igual a cada uma, o que facilita a formação dos preços que as cooperativas fornecedoras cobram da cooperativa matriz pelos produtos que lhe fornecem. Quarenta e cinco por cento dos excedentes são colocados em um fundo de reserva destinado principalmente a financiar novos investimentos3.
[3] Esse fundo é indivisível, ou seja, jamais poderá ser dividido entre os sócios. Fundos indivisíveis são criados para garantir a sobrevivência da cooperativa, nos casos em que sócios resolvam se retirar dela. Estes têm direito a receber sua parte do patrimônio não indivisível. $O$ dinheiro depositado no fundo indivisível continuará pertencendo aos sócios que permanecem na cooperativa. Os outros $55 \%$ dos excedentes são dos sócios, mas sólhes será entregue anos depois que deixarem a cooperativa. 
[4] Ainda em 1959, foi criada a Lagun Aro, a entidade de previdência do grupo. Na época as cooperativas estavam excluídas do sistema previdenciário oficial.
Essas regras colocam os interesses da coletividade claramente acima dos interesses individuais, tanto das cooperativas singulares como dos sócios. A elas deve ser atribuída a notável coesão que permitiu ao grupo se desenvolver notavelmente ao longo dos últimos 55 anos. Com o aumento do número de cooperativas, o grupo criou instituições de apoio, na forma de cooperativas de segundo grau cujos sócios são as cooperativas singulares. Em 1959, por insistência do padre Arizmendi, foi criada a Caja Laboral Popular - uma cooperativa de crédito que hojeé o grande banco do grupo, cuja divisão empresarial incuba as novas cooperativas ${ }^{4}$.

Os órgãos de direção de cada cooperativa de segundo grau são formados por representantes dos trabalhadores da própria cooperativa e dos trabalhadores das cooperativas singulares, geralmente em proporções iguais. Em 1969, a Caja promoveu a fusão de nove pequenas cooperativas de consumo, dando origem à Eroski, hoje a maior empregadora do grupo e uma das maiores redes de supermercados da Espanha. Enquanto cooperativa de consumo, sua direção é partilhada por igual por representantes dos consumidores associados a ela e dos trabalhadores que nela atuam.

O tema central do estudo de Mondragon é o efeito das crises sobre o grupo cooperativo e de que modo este as enfrentou. Em 1986, a Espanha aderiu ao Mercado Comum Europeu, abrindo o seu mercado interno às importações dos outros integrantes do Mercado Comum.A entrada dessas mercadorias no país captou boa parte da clientela que antes comprava os produtos da indústria nacional, inclusive das cooperativas do grupo de Mondragon. A crise se manifestou na forma de aguda queda das vendas, obrigando as cooperativas atingidas a reduzir a produção, deixando parte dos seus sócios sem trabalho.

O grupo cooperativo enfrentou a crise priorizando a preservação dos empregos. O caso de cada cooperativa atingida pela crise era estudado pela Caja em conjunto com a Lagun Aro, a cujo cargo estava o pagamento de seguro-desemprego aos associados. O salvamento dessas cooperativas geralmente exigia mudanças da linha de produção ou da estrutura de marketing, corte dos salários e/ou reforço do capital da cooperativa mediante contribuições dos trabalhadores. Apenas em casos extremos exigia-se redução de postos de trabalho.As propostas de medidas para o enfrentamento da crise eram submetidas a extensas consultas aos membros das cooperativas ameaçadas e naturalmente surgiam contrapropostas, o que exigia votações sucessivas até a formação de um consenso.

O êxito econômico inegável de cooperativas de modestos ceramistas, como no caso da Ceralep, ou de não menos modestos pescadores e mergulhadores, como os da cooperativa de Natividad, combina 
perfeitamente com a pujança de extensos complexos ou corporações, como demonstram os casos de Desjardins e de Mondragon. Em pequena ou grande escala, as cooperativas são viáveis mesmo quando enfrentam circunstâncias inóspitas das crises provocadas pelo capital financeiro desregulado. Sua capacidade de resistir a quedas inesperadas da demanda é notável, resistência que é fruto sobretudo da solidariedade entre membros das cooperativas e das comunidades em que as cooperativas se localizam, como evidenciam os casos de Ceralep e Mondragon. É difícil exagerar a oportunidade e a importância desta obra. Ela merece a leitura atenta e o debate engajado de todos que se preocupam com os perigos e as oportunidades que a presente crise apresenta.

PAUL SINGERé professor titular da FEA-USP e titular da Secretaria Nacional de Economia Solidária (SENAES). 